\title{
Indoor decorating and refurbishing materials and furniture volatile organic compounds emission labeling systems: A review
}

\author{
LIU WeiWei ${ }^{1}$, ZHANG YinPing $^{1 *}$, YAO Yuan ${ }^{1} \&$ LI JingGuang ${ }^{2}$ \\ ${ }^{1}$ Department of Building Science, Tsinghua University, Beijing 100084, China; \\ ${ }^{2}$ Shanghai Research Institute of Building Sciences (Group) Co., Ltd., Shanghai 201108, China
}

Received January 6, 2012; accepted March 1, 2012

\begin{abstract}
The volatile organic compounds (VOC) emitted from indoor decorating and refurbishing materials and furniture is recognized as one of the main causes of bad indoor air quality, which has resulted in serious economic losses. In European countries and the U.S., labeling systems for indoor decorating and refurbishing materials and furniture were established to address this issue with good effect. This paper is a review of these existing labeling systems. The basic principle of the labeling systems is introduced. The technical, policy and operational parts of the labeling systems are then discussed. The research concentrates on target pollutants, their threshold values and the testing methods employed. Some problems were uncovered in these labeling systems: too many VOCs were targeted; the method to determine the threshold values was not very rigorous; the testing time was too long (7-28 d). Some China's special features in developing such system are stated. Therefore, as the world's largest national producer and consumer of wood based panels and furniture, China should learn from foreign experience of establishing labeling systems as much as it can. However China should not simply copy the foreign approaches but develop its own scientific labeling system for indoor decorating and refurbishing materials and furniture.
\end{abstract}

indoor air quality (IAQ), volatile organic compounds (VOCs), formaldehyde, emission, labeling, decorating and refurbishing materials, furniture

Citation: Liu W W, Zhang Y P, Yao Y, et al. Indoor decorating and refurbishing materials and furniture volatile organic compounds emission labeling systems: A review. Chin Sci Bull, 2012, 57: 2533-2543, doi: 10.1007/s11434-012-5208-x

Volatile organic compound (VOC) emissions from indoor decorating and refurbishing materials and furniture can be a significant source of indoor air pollution. Formaldehyde and a wide range of VOCs can be emitted, and concentrations can be particularly elevated in buildings following refurbishment [1-5]. It is notable that indoor VOC concentrations are higher in the Chinese mainland than overseas (Figures 1 and 2) [6,7]. Indoor air pollution can lead to sick building syndrome (SBS) [8,9], cause building related illnesses (BRI) [10] and multiple chemical sensitivities (MCS) [11] and has caused great economic loss. In the U.S. 40 billon dollars are lost per year due to poor indoor air quality [12] and 10.7 billon dollars are lost in China [13].

Three major strategies are available to solve indoor air

*Corresponding author (email: zhangyp@tsinghua.edu.cn) quality (IAQ) problems: pollutant source control, ventilation and air cleaning, among which pollutant source control is generally the most cost-effective and environmentally preferable to pollutant removal [14]. In order to control pollutant sources, labeling schemes for low VOC emission products were established in many countries around the world [15-20] (Table 1). The first environment-related label for products in the world is the German Blue Angel. It was created in 1978 (http://www.blauer-engel.de/en/blauer_ engel/index.php). Today about 11500 products in approximately 90 product categories carry the Blue Angel eco-label. It has had a significant number of successes in environmental and consumer policies. The experience tells us "One label says more than a thousand words".

China is currently the largest producer of wood based panels, coatings and furniture in the world [21-23]. As 
Table 1 Labeling schemes in various countries

\begin{tabular}{cl}
\hline Region & Labeling name (start year) \\
\hline & Germany Blue Angel(1978), GUT(1990), EMICODE(1997), AgBB(2000), Natureplus(2002) \\
& France NF Environment(1991), CESAT(2003), AFSSET(2004) \\
& Sweden Good Environmental Choice(1992), TCO(1992) \\
& Scandinavia Swan(1989), Austria Umweltzeichen(1990), EU Flower(1992), Netherlands Milieukeur(1992) \\
& Czech Republic Environmentally Friendly Products(1993), Croatia Environmental Friendly (1993) \\
& Spain Aenor(1993), Denmark ICL(1994), Hungary Environmentally Friendly(1994), Finland M1(1995) \\
& Slovakia Environmental Friendly Product(1996), Poland Eco Mark(1998), Portugal LQAI(2000) \\
\hline \multirow{3}{*}{ America } & U.S. Green Seal(1989), CRI Green Label Plus(1992), LEED(2000), Section 01350(2001), \\
& Greenguard(2001), CHPS(2002), SCS Indoor Advantage(2004), BIFMA(2005), Floorscore(2005), \\
& CARB(2008), Indoor air PLUS(2009) \\
& Canada Environmental Choice(1988), Brazil Environmental Quality(1993) \\
& Australia Environmental Choice(1991), New Zealand Environmental Choice(1992) \\
\hline Australia & Taiwan (China) Green Mark(1992), Hong Kong (China) Eco-label(1995), Green Label(2000) \\
& Japan Eco Mark(1989), India Ecomark(1991), South Korea Eco-label(1992) \\
& Singapore Green Label(1992), Israel Green Label(1993), Thailand Green Label(1993) \\
& Malaysia Eco-label(1996), Philippines Green Choice(2001) \\
\hline
\end{tabular}

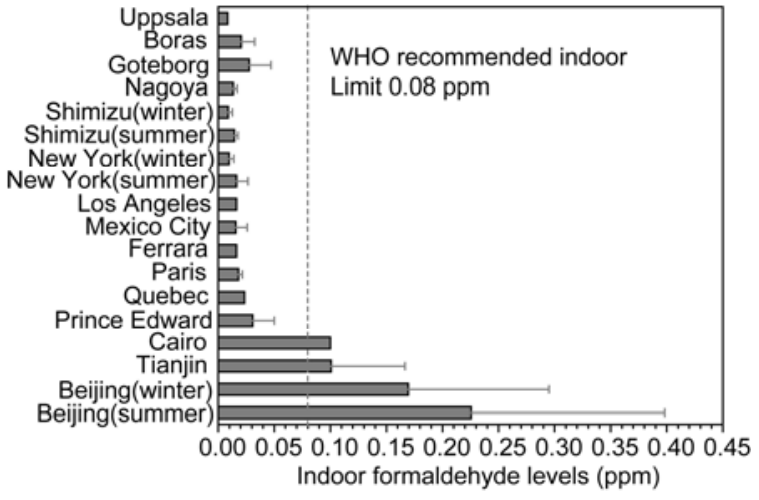

Figure 1 Indoor air formaldehyde concentrations of households in various cities [6].

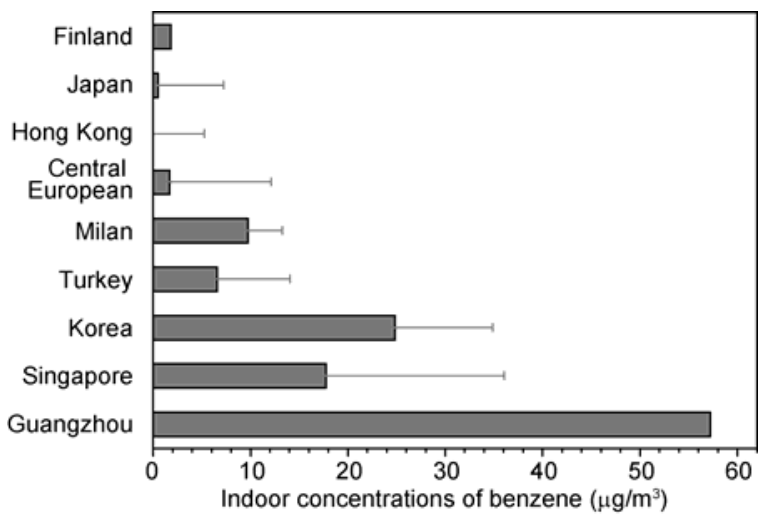

Figure 2 Indoor air benzene concentrations in various countries or regions.

important indoor pollutant sources, close attention is paid to indoor decorating and refurbishing materials and furniture. Establishing a labeling scheme following the example of Europe and the U.S. will be a good step toward improving indoor air quality in China. China should not simply copy the foreign models, but should rather consider its own spe- cial features when developing this labeling system. This paper is intended to provide a comprehensive review of the existing labeling schemes: (1) so as to learn what they do and how these schemes implement indoor materials and products labeling; (2) so that when considering the national conditions in China, we can point out which approaches are inappropriate for China. This work prepares the way for establishing a Chinese labeling scheme for indoor decorating and refurbishing materials and furniture VOC emissions.

\section{Principle of labeling}

Labeling of a product is a statement which means product quality has met specific criteria. The primary task of establishing indoor decorating and refurbishing materials and products VOC emission labeling schemes is to determine target pollutants, that is to say, it should be determined which pollutants must be included in the labeling. Target pollutant species included in various labeling schemes are very different. The number of target pollutants ranges from a few to more than one hundred. The second step is to determine threshold values for the target pollutants. Threshold values are those that target pollutants cannot exceed. Threshold values take different forms in the various labeling schemes. In some labeling schemes thresholds are concentration values emitted from a specific emission area. There are also threshold values that are emission rate per unit area. Comparing test results of specimens with the threshold values, we can judge whether the specimens are qualified. With target pollutants and threshold values, the next step is to determine the testing method that is the way to obtain VOC emission results. Existing labeling schemes commonly use the chamber test method (Figure 3). The testing principle is as follows: load the specimen into the chamber whose temperature and humidity are constants; supply the 


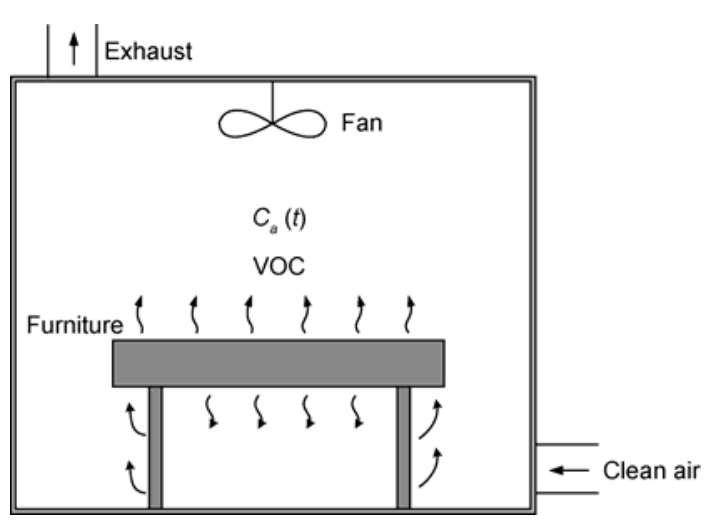

Figure 3 Schematic diagram of chamber test.

chamber with clean air at a constant flow rate and then the air mixed with VOC emission from specimen is exhausted through an air outlet port where VOC concentrations can be determined.

When it is assumed that: the air concentration in the chamber is perfectly mixed; the chamber is air tight except for the constant clean air supply; there are no chemical reactions inside the chamber; the air supplied into the chamber is clean; the adsorption of VOC on the chamber's interior surfaces is negligible, the VOC mass balance equation in the chamber is

$$
V \frac{\mathrm{d} C_{\mathrm{a}}}{\mathrm{d} t}=E A-Q C_{\mathrm{a}},
$$

where $V$ is chamber volume $\left(\mathrm{m}^{3}\right), t$ is time (specimen loading, door closing time is zero) (h), $C_{\mathrm{a}}$ is VOC concentration in the chamber $\left(\mathrm{mg} / \mathrm{m}^{3}\right), E$ is emission factor of the specimen $\left(\mathrm{mg} /\left(\mathrm{m}^{2} \mathrm{~h}\right)\right), A$ is emission area of the specimen $\left(\mathrm{m}^{2}\right)$, and $Q$ is clean air flow rate supplied into the chamber $\left(\mathrm{m}^{3} / \mathrm{h}\right)$.

At steady state or when the emission rate changes very slowly with time, the emission factor can be calculated according to equation:

$$
E \approx \frac{Q}{A} C_{\mathrm{a}} .
$$

In some labeling schemes when the emission factor $E$ is obtained, the VOC concentration in the reference room $C_{s}$ which is used for labeling is calculated according to equation:

$$
C_{s}=\frac{A_{s} E}{Q_{s}},
$$

where $C_{s}$ is VOC concentration in the reference room $\left(\mathrm{mg} / \mathrm{m}^{3}\right), A_{s}$ is emission area of specimen in the reference room $\left(\mathrm{m}^{2}\right), E$ is emission factor of specimen $\left(\mathrm{mg} /\left(\mathrm{m}^{2} \mathrm{~h}\right)\right)$, and $Q_{s}$ is air flow rate supplied into the reference room $\left(\mathrm{m}^{3} / \mathrm{h}\right)$.

\section{Parts of labeling}

Based on these basic principles, VOC emission labeling schemes for indoor decorating and refurbishing materials and products have been established in many countries. The common feature of existing labeling systems is that they all consist of three parts: technical, operational and policy parts. Figure 4 shows details of every part and the relationships among them. The following studies will be carried out according to points described in the framework.

\subsection{Technical part}

(i) Target pollutants. In order to establish a labeling scheme, we should first determine the target pollutants. Target pollutants are the chemicals required to be analyzed in the test. Target pollutants in existing labeling schemes could be roughly divided into 2 parts: carcinogenic substances and VOC (including TVOC and aldehydes).

The carcinogens have been classified by different organizations, e.g. the European Union (EU) and the international agency for research on cancer (IARC), into various groups expressing different potential risks for people. The EU scheme which classifies the carcinogenic substances into three categories is used in many European labeling schemes [24]: category 1 includes substances known to be carcinogenic to people; category 2 includes substances which should be regarded as if they were carcinogenic to people; category 3 includes substances which cause concern for people owing to a possible carcinogenic effect. In the

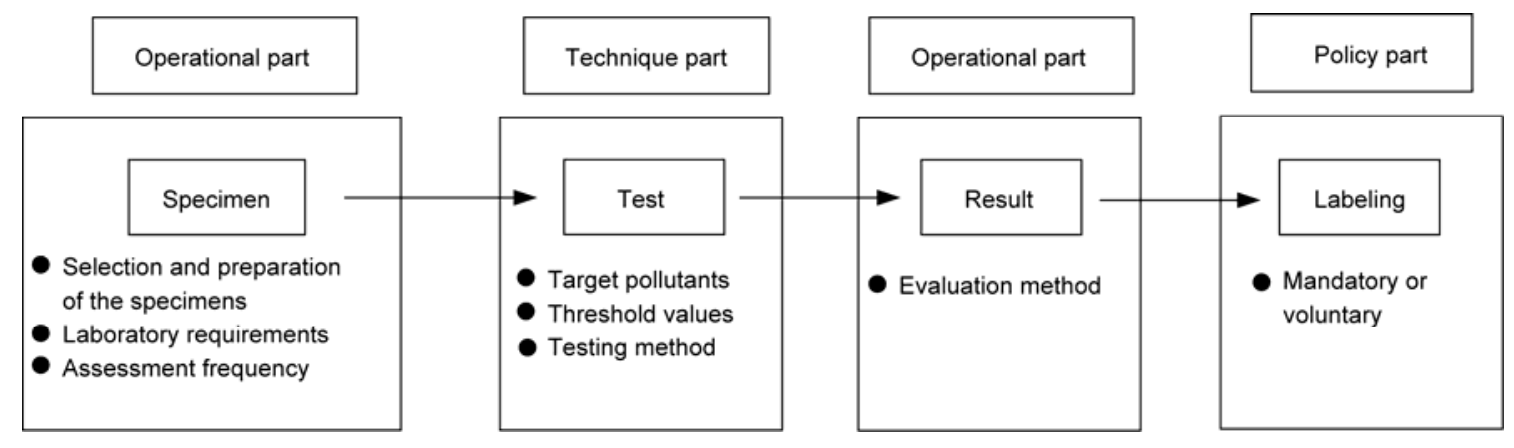

Figure 4 Framework of labeling scheme. 
German AgBB labeling scheme [25], emissions of carcinogenic substances belonging to categories 1 and 2 according to EU Directive 67/548/EEC, are required to be tested. The limit values of carcinogenic substances according to this EU directive are also specified in German Blue Angel [26] and EMICODE [27] labeling schemes. American labeling scheme shave scarcely any classification and restrictions of carcinogenic substances.

In European labeling schemes the lowest concentration of interest (LCI) is the most widely used concept. It is a substance-specific value for health-related evaluation of emissions from building products [25]. VOCs that have been considered and assessed by national or international committees are used in development of the LCI. The initial LCI list was published in ECA report No.18 [24] which included 163 VOCs. This list was slightly modified and adopted in the AgBB [25] LCI that included 170 VOCs, and the French AFSSET [28] LCI that included 164 VOCs. AgBB LCI is also adopted in Blue Angel and GUT. The Danish ICL [29] does not use LCI. VOCs whose concentrations have exceeded the odor and irritation threshold values should be considered. The Finnish M1 [30] labeling scheme only has restrictions for TVOC, formaldehyde, ammonia and carcinogenic compounds and there are no other individual compound restrictions. In American labeling schemes, chronic reference exposure levels (CRELs) are most widely used. These CRELs were developed by the office of environmental health hazard assessment in the California environmental protection agency (Cal/EPA OEHHA). CRELs are inhalation concentrations to which the general population, including sensitive individuals, may be exposed for long periods (10 years or more) without the likelihood of serious adverse systemic effects other than cancer. In California Section 01350 [31] OEHHA's new CRELs are adopted which include 35 VOCs (including formaldehyde). The SCS labeling scheme [32] uses California Section 01350 as its labeling basis. Besides using CREL, the GREENGUARD labeling scheme [33] also uses a threshold limit value (TLV), an industrial workplace standard that includes 355 VOCs. The American business and institutional furniture manufacturer's association (BIFMA) labeling scheme [34] includes 4 chemical limits of indoor air concentrations due to emissions from furniture and seating: TVOC, formaldehyde, total aldehydes and 4phenylcyclohexene which are taken from U.S. Green Building Council (USGBC)'s "Green Building Rating system For Commercial Interiors LEED" [35]. It can be concluded that most of the labeling schemes include more than one hundred target pollutants, like AgBB, AFSSET, Blue Angel, GUT and GREENGUARD. Since China's IAQ research development is still in its infancy, these labeling schemes include too many target compounds to be easily adopted. Different raw materials and production processes of indoor decorating and refurbishing materials and furniture may lead to different VOC emission performance.
Therefore VOC emissions from indoor decorating and refurbishing materials and furniture in China may be different from those found in Europe and America. Target pollutants should be determined based on VOC emissions from indoor decorating and refurbishing materials and furniture that are on the market in China. This means that indoor decorating and refurbishing materials and furniture should be tested to determine what kinds of VOCs are emitted from them. The main pollutants could then be selected as the target pollutants.

Total volatile organic compound (TVOC) is an important concept that is controversial in the academic field. In ISO 16000-6 [36], TVOC is the sum of volatile organic compounds sampled on Tenax TA, which elute between and including n-hexane and n-hexadecane, are detected with a flame ionization detector or mass spectrometric detector. Some research [37] is inconclusive with respect to TVOC as a risk index for health and comfort effects in buildings since compositions of the pollutants may be very different under the same TVOC concentration, and that may cause very different health risks. Therefore there is at present an inadequate scientific basis on which to establish limit values for TVOCs. The TVOC indicator can be used for sensory irritation [38]. Others [39,40] consider that although TVOC is a crude way of describing the occurrence of VOC in indoor air, it may still be useful in testing of materials and as an indicator of insufficient or poorly designed ventilation. In European labeling schemes, TVOC is used except in the Danish ICL. In the U.S., California Section 01350 does not include TVOC but BIFMA, LEED and GREENGUARD add it to their schemes.

(ii) Threshold values. Threshold values are the maximum allowable values for VOC emissions. Comparing test results of specimens with these threshold values, we can judge whether the specimens are qualified. A few labeling schemes' threshold values are emission factors, like the Finnish M1, Portuguese LQAI and Austrian Umweltzeichen [15]. Threshold values of most labelling schemes are emission concentrations from the specimen. Figures 5 and 6 show threshold values of formaldehyde and TVOC in various labeling schemes $[15,33,34]$. It can be seen that the threshold values among various labeling schemes are very different.

The primary reason for this phenomenon is the various requirements of the testing time. Figure 5 shows the testing time could be $1,3,7$ or $28 \mathrm{~d}$. Secondly, the testing objects are different. GUT labeling scheme is only for textile floor coverings; AgBB, CESAT, Natureplus, LQAI and Blue Angel are for several types of construction products and indoor products; BIFMA is only for office furniture; GREENGUARD is for office furniture and school and child related indoor materials and products. Thirdly, different labeling schemes may adopt different VOC risk assessment databases and have personalized treatment. Take AgBB LCI value for example [25]. LCI values come from occupational 


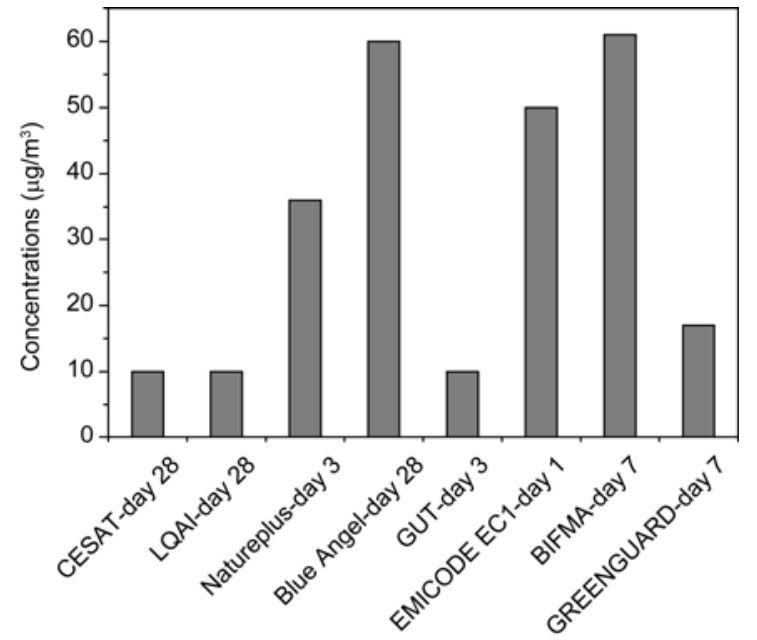

Figure 5 Formaldehyde threshold values in various labeling schemes.

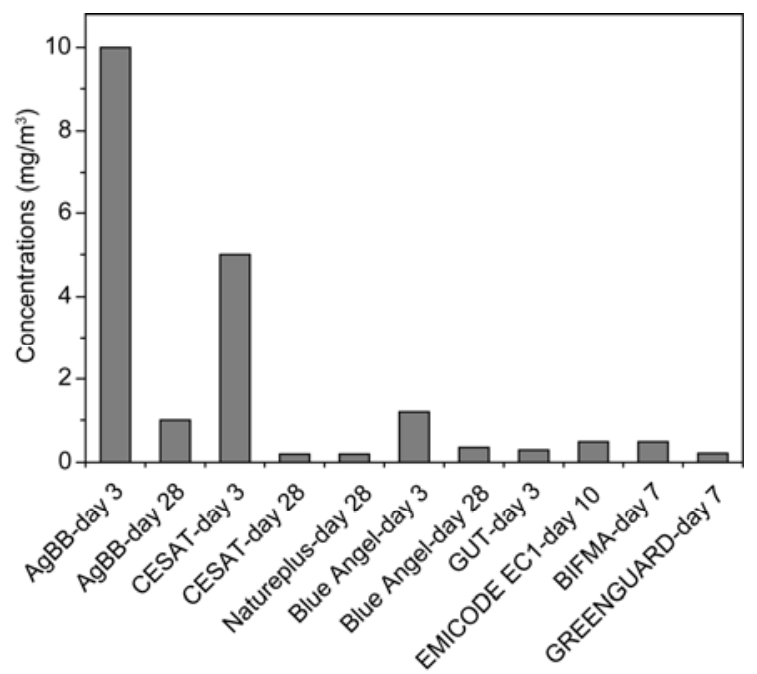

Figure 6 TVOC threshold values in various labeling schemes.

exposure limit values (OELVs) in workplace air and EU category 3 (Directive 67/548/EEC). Since various exposure times and sensitivities should be considered for the general population in comparison to workplace conditions, the relevant OELVs are generally divided by 100 applying safety factors (1000 for carcinogenic substances of EU category 3). For the evaluation of each compound $i$ the ratio $R_{i}$ is established (eq. (4)).

$$
R_{i}=C_{i} / \mathrm{LCI}_{i},
$$

where $C_{i}$ is the chamber concentration of compound $i$. The sum of $R_{i}$ should be not more than 1 (eq. (5)).

$$
R=\sum R_{i} \leqslant 1 \text {. }
$$

AFSSET LCI is similar to AgBB LCI, but some chemicals in AFSSET use different standard values and apply different safety factors. So AFSSET LCI is different from AgBB LCI. In the U.S., California Section 01350 chooses to use $1 / 2$ of CREL as limit values. Note that there is no scientific explanation for the question of why AgBB uses 100 or 1000 , or why California Section 01350 uses $1 / 2$ as safety factor. Figure 7 shows the very big differences between AgBB LCI, AFSSET LCI and 1/2 CREL for some target compounds. In addition, the guidance value for formaldehyde in California Section 01350 is $16.5 \mu \mathrm{g} / \mathrm{m}^{3}$ now but will be $9 \mu \mathrm{g} / \mathrm{m}^{3}$ beginning in 2012. The formaldehyde guidance value is $100 \mu \mathrm{g} / \mathrm{m}^{3}$ in the Chinese indoor air quality standard GB/T 18883-2002 [41]. It seems that the limit value of formaldehyde in the Californian standard is too strict for China. In some labeling schemes VOC concentrations in a reference room are calculated according to eq. (3) and then are compared with threshold values. One reference room was defined in the Danish ICL (Table 2) and it was also used in ISO 16000-9 [42] and the Finnish M1. In American labeling schemes many reference rooms, including offices, classrooms and family rooms are established (Table 2) $[43,44]$. It is concluded that there are very big differences among threshold values of various labeling schemes in Europe and America. The common practice of determining threshold values is to select exposure assessment thresholds' specific multiplying factor. Some exposure assessment's limit values are occupational exposure limit values and there is generally no scientific basis for selecting the specific factor. When we determine threshold values of target pollutants in China, we should consider the indoor air quality standard GB/T 18883-2002. This would mean that decorating and refurbishing materials and furniture that are loaded in the room must ensure that the indoor air quality meets the standard. Indoor VOC concentrations are related to the materials and the amount of furniture used in the room, therefore the amount of decorating and refurbishing materials and furniture in homes should be known.

(iii) Testing method-Objective test. There are generally two means to test formaldehyde emissions of the products in existing labeling schemes: the content test and the chamber test. Wood based panels can emit formaldehyde

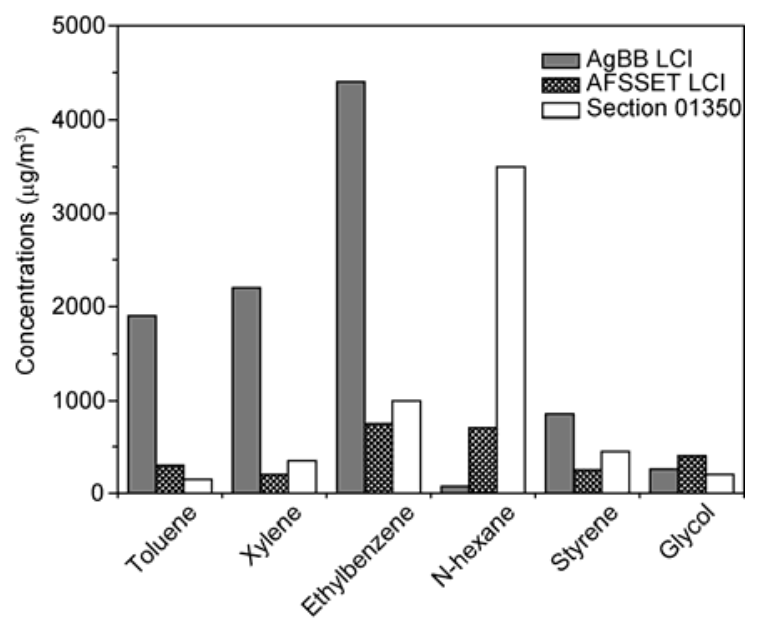

Figure 7 Comparison of AgBB LCI, AFSSET LCI and CA Section 01350 . 
Table 2 Characteristics of the reference rooms in European and American labeling schemes

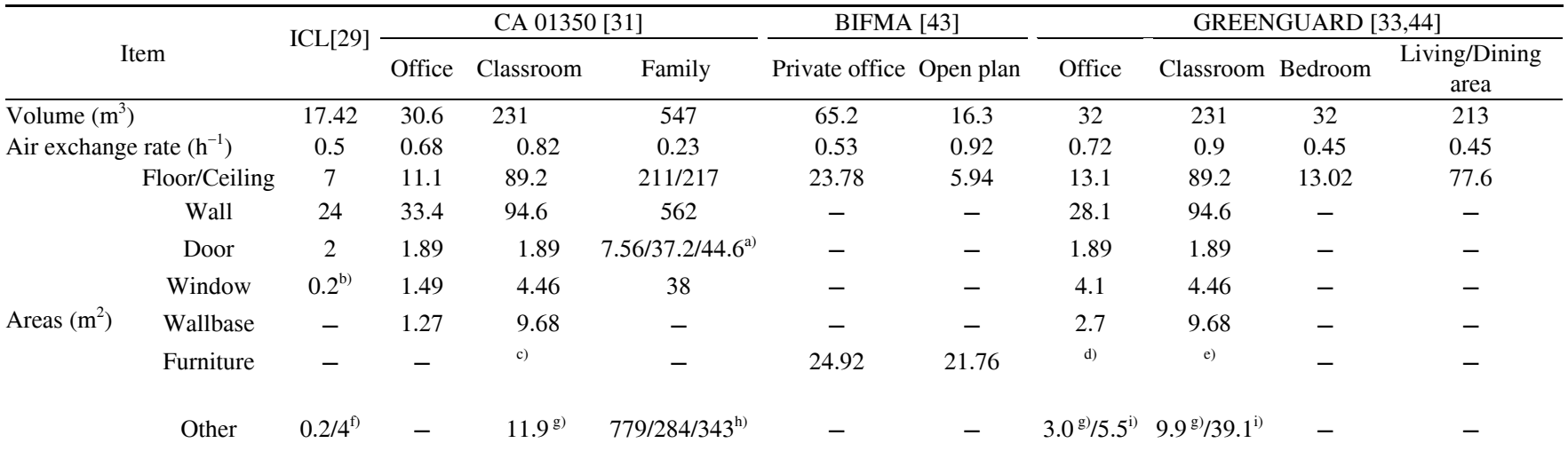

a) Exterior doors/Interior doors/Closet doors; b) window frame; c) 27 sets of desks and seatings; d) shelving/bookcases/counter tops 20 m², worksurface area $3.2 \mathrm{~m}^{2}, 1$ set of office furniture; e) 27 sets of children's desks and seatings, 1 set of teacher's desk and chair, shelving/bookcases/counter tops $7.81 \mathrm{~m}{ }^{2}$, worksurface area $12.3 \mathrm{~m}^{2}$; f) sealant/Fixtures; g) markerboards; h) interior wallboard paint/thermal insulation/acoustic insulation; i) HVAC duct material.

due to the use of urea-formaldehyde resin [45]. The Nordic swan labeling scheme [46] used the perforator method in accordance with EN120 [47] to determine the content of free formaldehyde in wood panels. The perforator method is a very old and unscientific method because the value measured by the perforator method is far greater than the emittable content at room temperature, which should be our target value $[48,49]$. In China, we also have the perforator test method for determining formaldehyde emissions of particle and density boards [50,51] with the same problems. The chamber test method much more widely used in all the labeling schemes. It can provide people with emission data that is useful for evaluating the impact of building product emissions on the indoor air quality. There are specific standards for the chamber test method. American labeling schemes usually follow the American Society for Testing and Materials (ASTM) standards and European labeling schemes follow the International Organization for Standardization (ISO) or European (EN) standards. Table 3 shows chamber test method standards that widely used at present [42,52-57].

Air sample collection and analysis systems should be specified in the chamber test method. Samples for analyses of aldehydes and VOCs are required to be collected and analyzed using instrumental methods that are capable of positively identifying and quantifying individual VOCs and aldehydes. The methods used in the various labeling schemes are basically the same. VOCs are collected using a Tenax tube and then thermally desorbed to a GC/MS system for identification and quantification. Aldehydes are collected onto DNPH (2,4-dinitrophenylhydrazine) cartridges and analyzed by high performance liquid chromatography (HPLC) with ultraviolet (UV) detection. ISO and ASTM have standards of detailed methods for VOC and aldehyde determination. ISO 16000-6 [36] and ASTM D6196 [58] are for VOCs. ISO 16000-3 [59] and ASTM D5197 [60] are for aldehydes.

Chambers for VOC emissions tests should satisfy corre-

Table 3 Chamber test method standards

\begin{tabular}{|c|c|c|c|c|c|c|c|}
\hline No. & Target pollutants & Specimen & $\begin{array}{c}\text { Volume } \\
\left(\mathrm{m}^{3}\right)\end{array}$ & $\begin{array}{c}\text { Temperature } \\
\left({ }^{\circ} \mathrm{C}\right) \\
\end{array}$ & $\begin{array}{c}\text { Relative humidity } \\
(\% \mathrm{RH})\end{array}$ & $\begin{array}{c}\text { Air exchange } \\
\text { rate }(1 / \mathrm{h})\end{array}$ & $\begin{array}{l}\text { Loading factor } \\
\left(\mathrm{m}^{2} / \mathrm{m}^{3}\right)\end{array}$ \\
\hline $\begin{array}{c}\text { ISO } \\
12460-1[52]\end{array}$ & Formaldehyde & Wood based panels & 1 & 23 & 50 & 1 & 1 \\
\hline EN717-1[53] & Formaldehyde & Wood based panels & $\begin{array}{c}0.225 / 1 / \geqslant \\
12\end{array}$ & 23 & 45 & 1 & 1 \\
\hline $\begin{array}{c}\text { ASTM } \\
\text { E1333[54] }\end{array}$ & Formaldehyde & Wood products & $\geqslant 22$ & 25 & 50 & 0.5 & $0.95 / 0.43 / 0.26$ \\
\hline $\begin{array}{c}\text { ASTM } \\
\text { D6007[55] }\end{array}$ & Formaldehyde & Wood products & $0.02-1$ & 25 & 50 & b) & b) \\
\hline $\begin{array}{c}\text { ASTM } \\
\text { D6670[56] }\end{array}$ & Formaldehyde and VOC & Indoor materials/products & c) & $23^{\mathrm{d})}$ & $50^{\mathrm{d})}$ & $0.5^{\mathrm{d})}$ & - \\
\hline $\begin{array}{c}\text { ASTM } \\
\text { D5116[57] }\end{array}$ & Formaldehyde and VOC & Indoor materials/products & $\leqslant 5$ & e) & e) & e) & e) \\
\hline
\end{tabular}

a) Annex B in ISO 16000-9: floor 0.40, wall 1.38, sealant 0.011; b) air exchange rate/loading factor=0.526/1.173/1.905/3.846 m/h; c) room-size chamber; d) only an example; e) examples test matrix are given in Table 1 in ASTM D5116. 
sponding performance requirements. In order to assess the overall performance of the chamber, Zhang et al. [61] developed the standard VOC emission source whose emission rate could be measured independently from the chamber testing method. In Zhang et al.'s study, an uncovered petri-dish containing liquid VOC was used as a reference emission source. The reference source was placed in the test chamber and its weight loss due to evaporation was measured by an electronic balance to determine the reference emission rate. The chamber testing result was compared with the reference value to obtain the difference. ASTM D6670 [56] adopted this method. The overall performance of the chamber was quantified by the relative difference $\delta$ (eq. (6)). For quality assurance, the time average of $\delta$ should be within $\pm 15 \%$.

$$
\delta=\frac{R}{R_{r}}-1
$$

where $R$ is the emission rate calculated from the VOC concentration in the chamber, and $R_{r}$ is the reference emission rate determined by electronic balance.

However, this method is imperfect. Due to the petri-dish being uncovered during testing, the ambient air flow above the petri-dish could greatly influence the evaporation rate, making the emission rate unstable [62]. Cox et al. [63,64] developed a new standard reference VOC emission source by dissolving toluene into a polymethyl pentene (PMP) polymer substrate. Chamber test concentration results were compared with emission model values. However, uncertainty of emission rate is not easy to evaluate because of the uncertainty of the emission model itself. In addition, the emission rate of the PMP film changed with time, which may be not be appropriate for testing over a long period [62].

Various labeling schemes have different testing sched- ules (Figure 8). For most of the European labeling schemes, the entire duration of the emission test is $28 \mathrm{~d}$. During these $28 \mathrm{~d}$, one or several chamber air samples may be collected at day 1 , day 3 , day 10 or day 28. In the American labeling schemes, test periods are always 7 or $14 \mathrm{~d}$. It can be seen that existing labeling schemes need long test times ( 7 or 28 d). The testing methods of European labeling schemes are developed from EN 13419-1 (superseded by EN ISO 16000-9). In EN 13419-1 the test period is $28 \mathrm{~d}$, so the test period of the labeling scheme is $28 \mathrm{~d}$. But EN 13419-1 does not explain why the test period is $28 \mathrm{~d}$. BIFMA has given an explanation for their test schedule. The minimum time between the completion of installation and occupancy is $16 \mathrm{~d}$. Therefore the standard [65] recommends a 14-d testing period. However, analyses of furniture emission characteristics and past test data suggest that it is adequate to use 7-d test data to predict the VOC emission rates at the 14th day. That is why the test period is $7 \mathrm{~d}$. Testing times of 7-28 d are unnecessarily long, and may lead to a higher cost that increases the economic burden on the producer and thus hinder popularization and application of the labeling scheme.

It is worth mentioning that in order to shorten testing time to $7 \mathrm{~d}$, BIFMA [65] developed a power-law model for interpolation and extrapolation (eq. (7)). The power-law model can be used to predict the emission factor at $14 \mathrm{~d}$ based on the emission results at day 3 and day 7 .

$$
E=a t^{-b} \text {, }
$$

where $E$ is the emission factor at time $t, a$ and $b$ are coefficients determined by

$$
\begin{aligned}
& b=\frac{\ln E_{1}-\ln E_{2}}{\ln t_{2}-\ln t_{1}}, \\
& a=E_{1} t_{1}^{-b}=E_{2} t_{2}^{-b},
\end{aligned}
$$

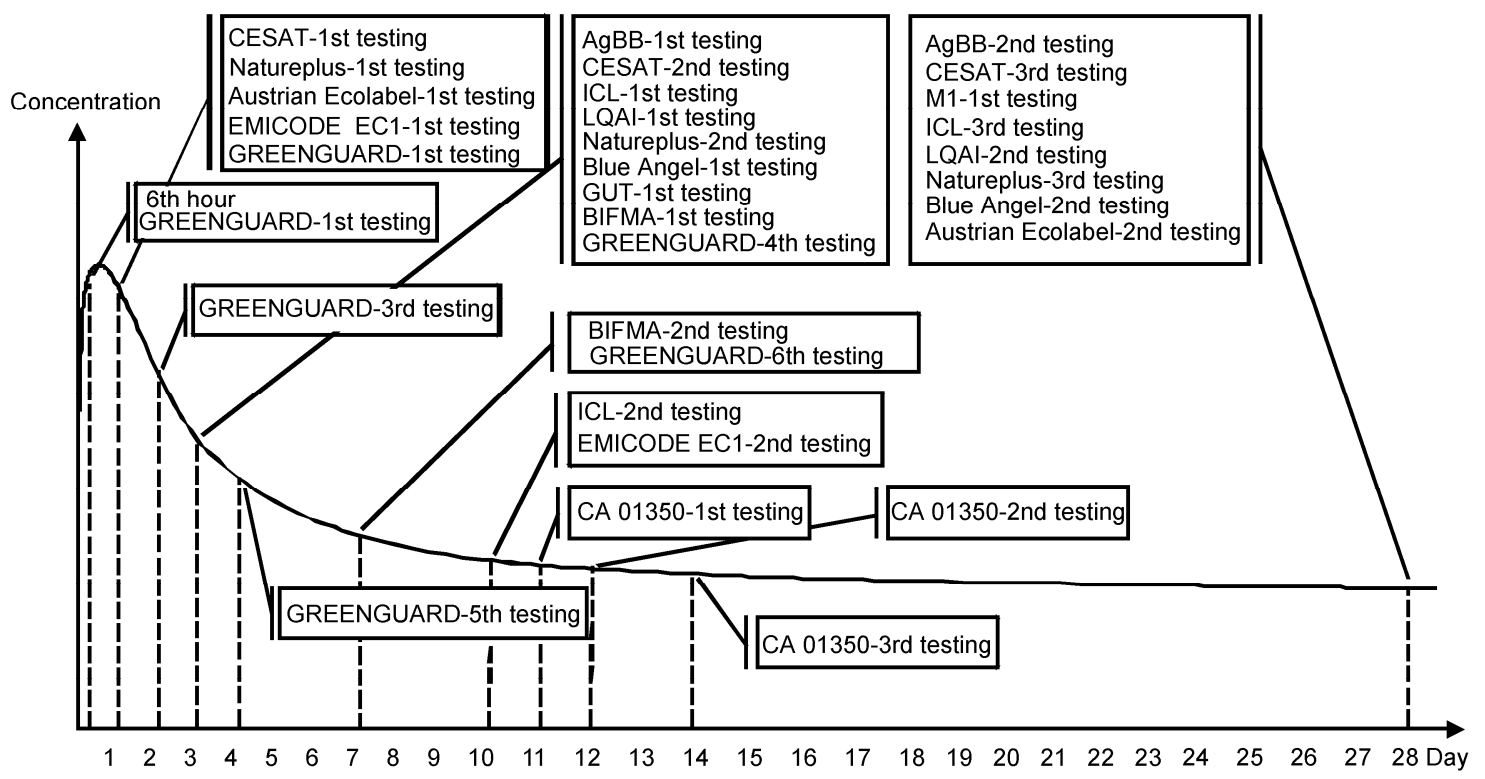

Figure 8 Testing time schedule of various labeling schemes. 
where $E_{1}$ and $E_{2}$ are emission factors corresponding to time $t_{1}$ and $t_{2}$ respectively.

It is noted that this power-law model is only an empirical model. It is pointed out in the standard that the power-law model is only used to predict the emission factor at $14 \mathrm{~d}$ or less. It therefore seems that application of the empirical model is limited. A next step would be to develop a mass transfer theoretical model to shorten testing time.

(iv) Testing method-Subjective test. Some VOCs may produce an odor nuisance which may affect the perception of the indoor air quality by people [66-69]. Therefore a sensory test isappliedin some labeling schemes. For example, the Danish ICL [29] specified that VOC emissions of the specimen placed in CLIMPAQ [70] were sniffed and evaluated by an untrained panel. They evaluate and report their first impression of acceptablility and odor intensity in Figure 9. The indoor air quality is regarded as acceptable at an acceptability greater than 0 and an odor intensity of less than 2. The Finnish M1 also have a sensory test. There is no sensory test in American labeling schemes.

\subsection{Policy part}

There are some differences in the legal status of various labeling schemes. In general, most labeling systems are typically voluntary for the manufactures. Market demand for low emitting materials is their main driving force. In these labeling schemes, M1, ICL and Blue Angel are promoted by governments. Natureplus is promoted by several retailer chains. BIFMA is promoted by an industry association. Some are promoted by a third-party organization, like SCS and GREENGUARD. There are also some mandatory labeling schemes. For example, CE marking of building products is mandatory within the European economic area; the AgBB scheme has become mandatory for all floorings materials [15], California air resources board (CARB) has released a statute to reduce formaldehyde emission from wood based panels.

In China, there are two types of certification for products: mandatory and voluntary that are managed by the certification and accreditation administration (CNCA). Mandatory certification is also known as China Compulsory Certification known as $3 \mathrm{C}$ or CCC for short. Up until the present, 3C includes 273 kinds of products, e.g. solvent based coatings

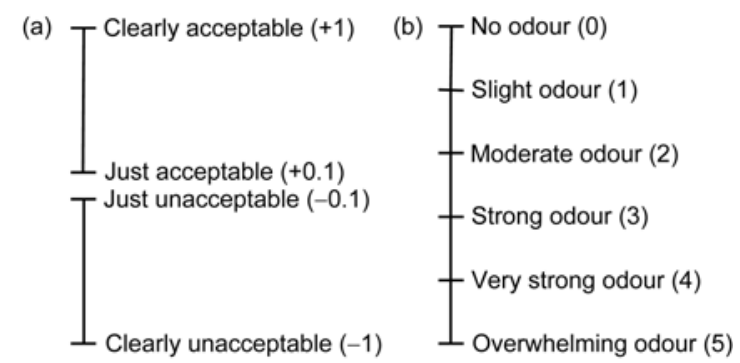

Figure 9 Sensory test [29]: (a) Acceptability; (b) odour intensity. for woodenware, porcelain tile, electrical sockets, electric fan and so on (http://www.xmciq.gov.cn/wsbs/jyjy/rzjg/3crz/ 201003/t20100315_30933.htm). Products included in 3C should get certified, otherwise they are not allowed to be imported from abroad to be sold or used in the market. Further study is needed to determine whether other indoor decorating and refurbishing materials and furniture can be entered into the $3 \mathrm{C}$ catalog.

\subsection{Operational part}

(i) Selection and preparation of test specimens. Samples selected for testing should be representative of the products manufactured under typical operating conditions. If test results are to be considered representative of a group of products or materials, a representative specimen that has the potential to have the highest VOC emissions should be selected from the group. Prescreening testing or other analysis by the manufacturer in consultation with the testing facility and certification agency may be necessary to determine representative specimens [65]. A sampling, storage and preparation procedure fortest specimens is clearly statedin ISO 16000-11 [71]. Samples must be stored immediately after collection in airtight, moisture-proof containers or packaging to prevent contamination and to preserve their chemical integrity by preventing subsequent VOC emission losses.

(ii) Assessment frequency. The emission test results can be considered valid and useful for supporting claims of low emitting product as long as the materials and components, manufacturing processes and packaging methods remain the same. Significant changes to one or more of these factors should be evaluated for possible effect on emission characteristics. If it is possible that the product emissions will increase as a result of a change being implemented, a new test should be conducted [65]. The manufacturer or certification organization should establish the schedule for routine laboratory retesting of samples. Often, biennial or even annual retesting is required [31].

(iii) Laboratory requirement. Laboratories should be maintained according to a quality management system (QMS) [31]. A laboratory's QMS and applicable test procedures should be conducted in accordance with ISO/IEC 17025 [72]. The best proof of quality of the laboratory conducting testing and evaluation of VOC emissions is that the laboratory is accredited for the test methods or at least has been validated through interlaboratory comparisons. Large-scale contrast tests have been carried out by laboratoies from Europe and the U.S. The test specimens were PVC flooring, carpet, paint and water-based liquid floor wax [73,74]. BIFMA has organized an inter-laboratory comparison study of the ANSI/BIFMA standard test method M7.1 using chairs as test specimens [75]. A reference VOC emission source has also been used in an inter-laboratory comparison study [76]. 
(iv) Certification method. There are three ways to certify the products. The first is a YES/NO method. If the product meets all the requirements of the labeling scheme, it will be certified and get labeling. Otherwise it can not get labeling. Most labeling schemes use this method. The second is a rating method. For example, in Finland building materials have been classified into three emission classes: M1, M2 and M3. Class M1 corresponds to the products with the lowest pollutant emission rates and class M3 indicates materials with the highest pollutantemission rates [77]. The rating method divides products into different grades that could meet the needs of various environmental conditions. Therefore it is convenient for users to buy products according to their own situations. The third method is the Danish LCI method. It would declare indoor-relevant time-value based on the results of the emission test. Indoor-relevant time-value means the time it takes to reach the acceptable indoor air quality for all emitted compounds in a standard room under standard conditions [78].

\section{Conclusions}

In Europe and the U.S., indoor decorating and refurbishing materials and furniturelabeling schemes were established to improve indoor air quality with goodeffect. Since China is now the primary producer of wood based panels, coatings and furniture in the world, it should learn from Europe and the U.S. so as to establish labeling schemes. China should fully consider China's national condition when establishing labeling schemes, and not simply copy the foreign models in their entirety. Some aspects of these foreign models that are inappropriate for China are as follows:

(1) Hundreds of VOCs are considered target pollutants in some labeling schemes. This is too many for China. Different raw materials and production processes of products may lead to different VOC emission performance. Therefore the large number of target pollutants in European and American labeling schemes may not be suitable for China. Instead China could determine target pollutants through indoor decorating and refurbishing materials and furniture VOC emission tests.

(2) The method to determine the threshold values is not that scientific. Some labeling schemes use occupational exposure limit values multiplying specific factors as threshold values. There is no scientific basis for selecting the specific factor. In China, determining the threshold value should simultaneously consider indoor air quality standard and the quantity of indoor decorating and refurbishing materials and furnitureused in the room.

(3) The testing time of 7-28 d is too long which leads to high testing cost which translates to a heavy economic burden on the manufacturers. This is not beneficial to popularizing and applying a labeling scheme. A theoretical model could be developed to shorten the testing time.
(4) The emission rate of a standard emission source (an uncovered petri-dish containing liquid VOC) is vulnerable to being influenced by the ambient air flow above the petri-dish. The emission rate of the standard emission source made by dissolving toluene into PMP changes over time. Both are not appropriate for testing the performance of a chamber.

This work was supported by Beijing Municipal Science and Technology Commission Projects (D09050603750802) and the Chinese National 12th Five-year Science and Technology Support Plan Project (2012BAJ02B01).

1 Chan C S, Lee S C, Chan W, et al. Characterisation of volatile organic compounds at hotels in southern China. Indoor Built Environ, 2011, 20: 420

2 Guo H, Kwok N H, Cheng H R, et al. Formaldehyde and volatile organic compounds in Hong Kong homes: Concentrations and impact factors. Indoor Air, 2009, 19: 206-217

3 Brown S K. Volatile organic pollutants in new and established buildings in Melbourne, Australia. Indoor Air, 2002, 12: 55-63

4 Yu C W F, Kim J T. Building pathology, investigation of sick buildings - VOC emissions. Indoor Built Environ, 2010, 19: 30-39

5 Lim S, Lee K, Seo S, et al. Impact of regulation on indoor volatile organic compounds in new unoccupied apartment in Korea. Atmos Environ, 2011, 45: 1994-2000

6 Zhang L P, Steinmaus C, Eastmond D A, et al. Formaldehyde exposure and leukemia: A new meta-analysis and potential mechanisms. Mutat Res, 2009, 681: 150-168

7 Adamkiewicz G, Choi H, Saborit J M D. WHO guidelines for indoor air quality: Selected pollutants. Technical Report, WHO regional office for Europe, Copenhagen, Denmark. 2010. 15-39

8 Reitzig M, Mohr S, Heinzow B, et al. VOC emissions after building renovations: Traditional and less common indoor air contaminants, potential sources, and reported health complaints. Indoor Air-Int J Indoor Air Qual Clim, 1998, 8: 91-102

9 Brinke T J, Selvin S, Hodgson A T, et al. Development of new volatile organic compound (VOC) exposure metrics and their relationship to "sick building syndrome" symptoms. Indoor Air-Int J Indoor Air Qual Clim, 1998, 8: 140-152

10 Dotgan C B, Dorgan C E, Kanarek M S, et al. Health and productivity benefits of improved indoor air quality. ASHRAE Trans, 1998, 104: 658-666

11 Zhu Y X, Zhang Y P, Li X T, et al. Built Environment (in Chinese). 2nd Ed. Beijing: China Building Industry Press, 2005. 146-148

12 Haymore C, Odom R. Economic effects of poor IAQ. EPA J, 1993, 19: 28-29

13 Zhang D. Nearly half of people in the world suffer from indoor air pollution (in Chinese). People's Daily. 2004-12-30

14 Spengler J D, Samet J M, McCarthy J F. Indoor Air Quality Handbook. New York: McGraw-Hill Companies Press, 2001

15 Kephalopoulos S, Koistinen K, Kotzias D. Report No.24-Harmonisation of indoor material emissions labelling systems in the EU: Inventory of existing schemes. Technical Report, European Collaborative Action, European Commission. 2005

16 Müller B, Dahms A, Bitter F, et al. Material labelling: Combined material emission tests and sensory evaluations. In: Strøm-Tejsen P, Olesen B W, Wargocki P, et al., eds. Proceedings of the 11th international conference on indoor air quality and climate, 2008 Aug 17-22, Copenhagen. Denmark: Technical University of Denmark, 2008. 1066

17 Neuhaus T, Oppl R. Comparison of emission specifications in the US and in Europe. In: Strøm-Tejsen P, Olesen B W, Wargocki P, et al, eds. Proceedings of the 11th international conference on indoor air quality and climate, 2008 Aug 17-22, Copenhagen. Denmark: Technical University of Denmark, 2008. 954 
18 Crump D, Däumling C, Winther-Funch L, et al. Report No.27Harmonisation framework for indoor material labelling schemes in the EU. Technical Report, European Collaborative Action, European Commission. 2010

19 Yao Y. Research on some key problems of furniture VOC emission labeling system (in Chinese). Disseration for the Doctoral Degree. Beijing: Tsinghua University, 2011. 4-6

20 Wolkoff P. Trends in Europe to reduce the indoor air pollution of VOCs. Indoor air, 2003, 13: 5-11

21 Kang Y J, Wang Y Y, Chi C. China's wood based panel production remained No.1 in the world (in Chinese). China's Green Times, 2008-12-30

22 Zhang H. China's coating production become No.1 for the first time (in Chinese). China's Building Materials News, 2010-4-8

23 Pelizzari S, Finzi U. World furniture outlook 2009/2010. Technical Report, Centre for Industrial Studies, Milano, Italy, 2010

24 Bluyssen P, Cochet C, Fischer M, et al. Report No.18-Evaluation of VOC emissions from building products-Solid flooring materials. Technical Report, European Collaborative Action, European Commission. 1997

25 German Committee for Health-related Evaluation of Building Products $(\mathrm{AgBB})$. A contribution to the construction products directive: Health-related evaluation procedure for volatile organic compounds emissions (VOC and SVOC) from building products. 2010

26 RAL German Institutefor Quality Assuranceand Certification. RAL-UZ 38, Low-emission wood products and wood-base products. 2002

27 German Association for the Control of Emissions in Products for Flooring Installation (GEV). GEV-Testing method-Detemination of volatile organic compounds for control of emissions from products for flooring installation. 2004

28 French Agency for Environmental and Occupational Health Safety (AFSSET). Procédure de qualification des émissions de composes organiques volatils par les matériaux de construction et produits de décoration (in French). 2009

29 Danish Society of Indoor Climate. Standard test method for determination of the indoor-relevant time-value by chemical analysis and sensory evaluation. 2003

30 The Building Information Foundation RTS. Emission classification of building materials: Protocol for chemical and sensory testing of building materials. 2004

31 California Department of Public Health. Standard method for the testing and evaluation of volatile organic chemical emissions from indoor sources using environmental chamber. 2010

32 Scientific Certification Systems (SCS), U.S. Environmental certification program-Indoor air quality performance. 2007

33 GREENGUARD Environmental Institute, U.S. GGTM.P066, Standard method for measuring and evaluating chemical emissions from building materials, finishes and furnishings using dynamic environmental chambers. 2007

34 American National Standards Institute (ANSI). ANSI/BIFMA X7.1, Standard for formaldehyde and TVOC emissions of low-emitting office furniture systems and seating. 2007

35 U.S. Green Building Council (USGBC). Green building rating system for commercial interiors. 2005

36 International Organization for Standardization (ISO). ISO 16000-6, Indoor air-Part 6: Determination of volatile organic compounds in indoor and test chamber air by active sampling on Tenax TA sorbent, thermal desorption and gas chromatography using MS/FID. 2004

37 Andersson $\mathrm{K}$, Bakke J V, Bjorseth O, et al. TVOC and health in non-industrial indoor environments-Report from a Nordic scientific consensus meeting at Langholmen in Stockholm, 1996. Indoor Air, 1997, 7: 78-91

38 Molhave L. Organic compounds as indicators of air pollution. Indoor Air, 2003, 13: 12-19

39 Berglun B, Clausen G, Ceaurriz J D, et al. Report No.19-Total volatile organic compounds (TVOC) in indoor air quality investigations. Technical Report, European Collaborative Action, European Commission. 1997
40 Molhave L, Clausen G, Berglund B, et al. Total volatile organic compounds (TVOC) in indoor air quality investigations. Indoor Air-Int J Indoor Air Qual Clim, 1997, 7: 225-240

41 General Administration of Quality Supervision, Inspection and Quarantine of the People's Republic of China. GB/T 18883, Indoor air quality standard (in Chinese). 2002

42 International Organization for Standardization (ISO). ISO 16000-9, Indoor air-Part 9: Determination of the emission of volatile organic compounds from building products and furnishing-emission test chamber method. 2006

43 Carter R D, Zhang J S. Definition of standard office environments for evaluating the impact of office furniture emissions on indoor VOC concentrations. ASHRAE Trans, 2007, 113: 466-477

44 GREENGUARD Environmental Institute, U.S. GGPS.001, GREENGUARD indoor air quality standard for building materials, finishes and furnishings. 2010

45 He Z K, Wei W J, Zhang Y P. Formaldehyde and VOC emissions at different manufacturing stages of wood-based panels. Build Environ, 2012, 47: 197-204

46 Nordic Ecolabelling Board. Swan labelling of panels for the building, decorating and furniture industry, Version 4.4. 2010

47 European Committee for Standardization (CEN). EN 120, Woodbased panels-Determination of formaldehyde content-Extraction method called perforator method. 1992

48 Wang X K, Zhang Y P. A new method for determining the initial mobile formaldehyde concentrations, partition coefficients, and diffusion coefficients of dry building materials. J Air Waste Manage Assoc, 2009, 59: 819-825

49 Xiong J, Zhang Y. Impact of temperature on the initial emittable concentration of formaldehyde in building materials: Experimental observation. Indoor Air, 2010, 20: 523-529

50 General Administration of Quality Supervision, Inspection and Quarantine of the People's Republic of China. GB/T 17657, Test methods of evaluating the properties of wood-based panels and surface decorated wood-based panels (in Chinese). 1999

51 General Administration of Quality Supervision, Inspection and Quarantine of the People's Republic of China. GB 18580, Indoor decorating and refurbishing materials-Limit of formaldehyde emissions of wood-based panels and finishing products (in Chinese). 2001

52 International Organization for Standardization (ISO). ISO 12460-1, Wood-based panels-Determination of formaldehyde release-Part 1: Formaldehyde emission by the 1-cubic-metre chamber method. 2007

53 European Committee for Standardization (CEN). EN 717-1, Woodbased panels-Determination of formaldehyde release-Part 1: Formaldehyde emission by the chamber method. 2004

54 American Society for Testing and Materials (ASTM). ASTM E1333, Standard test method for determining formaldehyde concentrations in air and emission rates from wood products using a large chamber. 2002

55 American Society for Testing and Materials (ASTM). ASTM D6007, Standard test method for determining formaldehyde concentration in air from wood products using a small scale chamber. 2002

56 American Society for Testing and Materials (ASTM). ASTM D6670, Standard practice for full-scale chamber determination of volatile organic emissions from indoor materials/products. 2007

57 American Society for Testing and Materials (ASTM). ASTM D5116, Standard guide for small-scale environmental chamber determinations of organic emissions from indoor materials/products. 1997

58 American Society for Testing and Materials (ASTM). ASTM D6196, Standard practice for selection of sorbents, sampling, and thermal desorption analysis procedures for volatile organic compounds in air. 2003

59 International Organization for Standardization (ISO). ISO 16000-3, Indoor air-Part 3: Determination of formaldehyde and other carbonyl compounds-Active sampling method. 2001

60 American Society for Testing and Materials (ASTM). ASTM D5197, Test method for determination of formaldehyde and other carbonyl compounds in air (active sampler methodology). 2003

61 Zhang J S, Nong G, Mason M, et al. Assessing the performance of full-scale environmental chambers using an independently measured 
emission source. In: Raw G, Claire A, Peter W, eds. The 8th International Conference on Indoor Air Quality and Climate, 1999 Aug 8-13, Edinburgh. London: Construction Research Communications Ltd, 1999. 5081-5086

62 Wei W J, Zhang Y P, Xiong J Y, et al. A standard reference for chamber testing of material VOC emissions: Design principle and performance. Atmos Environ, 2012, 47: 381-388

63 Cox S, Little J, Marand E. Developing a standard reference VOC emissions source. In: Strøm-Tejsen P, Olesen B W, Wargocki P, et al, eds. Proceedings of the 11th International Conference on Indoor Air Quality and Climate, 2008 Aug 17-22, Copenhagen. Denmark: Technical University of Denmark, 2008. 611

64 Cox S S, Liu Z, Little J C, et al. Diffusion-controlled reference material for VOC emissions testing: Proof of concept. Indoor Air, 2010, 20: 424-433

65 American National Standards Institute (ANSI). ANSI/BIFMA M7.1, Standard test method for determining VOC emissions from office furniture systems, components and seating. 2007

66 Bluyssen P M, Fernandes E D, Groes L, et al. European indoor air quality audit project in 56 office buildings. Indoor Air-Int J Indoor Air Qual Clim, 1996, 6: 221-238

67 Nielsen G D, Hansen L F, Wolkoff P. Chemical and biological evaluation of building material emissions.2. Approaches for setting indoor air standards or guidelines for chemicals. Indoor Air-Int J Indoor Air Qual Clim, 1997, 7: 17-32

68 Knudsen H N, Kjaer U D, Nielsen P A, et al. Sensory and chemical characterization of VOC emissions from building products: Impact of concentration and air velocity. Atmos Environ, 1999, 33: 1217-1230

69 Berglund B, Bluyssen P, Clausen G, et al. Report No.20-Sensory evaluation of indoor air quality. Technical Report, European Collaborative Action, European Commission, 1999

70 Gunnarsen L, Nielsen P, Wolkoff P. Design and characterization of the CLIMPAQ, chamber for laboratory investigations of materials, pollution and air quality. Indoor Air-Int J Indoor Air Qual Clim, 1994, 4: 56-62

71 International Organization for Standardization (ISO). ISO 16000-11, Indoor air - Part 11: Determination of the emission of volatile organic compounds from building products and furnishing-Sampling, storage of samples and preparation of test specimens. 2006

72 International Organization for Standardization (ISO). ISO/IEC 17025, General requirements for the competence of testing and calibration laboratories. 2005

73 Bortoli M D, Kephalopoulos S, Kirchner S, et al. Report No.21European inter-laboratory comparison on VOC emitted from building materials and products. Technical Report, European Collaborative Action, European Commission, 1999

74 Boroli M D, Colombo A. Report No.13-Determination of VOCs emitted from indoor materials and products-Interlaboratory comparison of small chamber measurements. Technical Report, European Collaborative Action, Commission of the European Communities, 1993

75 Zhang J, Mason M, Hodgson A, et al. An inter-laboratory comparison study of the ANSI/BIFMA standard test method M7.1 for furniture. In: Santanam S, Bogucz E A, Peters C, et al, eds. Proceedings of the 9th International Healthy Buildings Conference and Exhibition, 2009, Sep 13-17 Syracuse, NY, USA. Syracuse: Syracuse Center of Excellence in Environmental and Energy Systems, 2009. 799

76 Howard-Reed C, Liu Z, Benning J, et al. Diffusion-controlled reference material for volatile organic compound emissions testing: Pilot inter-laboratory study. Build Environ, 2011, 46: 1504-1511

77 Sariola L, Kukkonen E. Principles and new developments of the emission classification of building materials in Finland. In: Yang X, Zhao B, Zhao R, eds. Proceedings of the 10th International Conference on Indoor Air Quality and Climate, 2005, Beijing. Beijing: Tsinghua University Press, 2005. 3481-3485

78 Danish Society of Indoor Climate. General labelling criteria. 2004

Open Access This article is distributed under the terms of the Creative Commons Attribution License which permits any use, distribution, and reproduction in any medium, provided the original author(s) and source are credited. 